\title{
Late-summer sea ice thickness variability in the Arctic Transpolar Drift 1991-2001 derived from ground-based electromagnetic sounding
}

\author{
Christian Haas \\ Alfred Wegener Institute for Polar and Marine Research, Bremerhaven, Germany \\ Received 30 December 2003; revised 25 March 2004; accepted 14 April 2004; published 14 May 2004.
}

[1] Late-summer thickness distributions of large ice floes in the Transpolar Drift between Svalbard and the North Pole in 1991, 1996, 1998, and 2001 are compared. They have been derived from drilling and electromagnetic (EM) sounding. Results show a strong interannual variability, with significantly reduced thickness in 1998 and 2001. The mean thickness decreased by $22.5 \%$ from $3.11 \mathrm{~m}$ in 1991 to $2.41 \mathrm{~m}$ in 2001, and the modal thickness by $22 \%$ from $2.50 \mathrm{~m}$ in 1991 to $1.95 \mathrm{~m}$ in 2001. Since modal thickness represents the thickness of level ice, the observed thinning reflects changes in thermodynamic conditions. Together with additional data from the Laptev Sea obtained in 1993, 1995, and 1996, results are in surprising agreement with recently published thickness anomalies retrieved from satellite radar altimetry for Arctic regions south of $81.5^{\circ} \mathrm{N}$. This points to a strong sensitivity of radar altimetry data to level ice thickness. INDEX TERMS: 4207 Oceanography: General: Arctic and Antarctic oceanography; 4215 Oceanography: General: Climate and interannual variability (3309); 4540 Oceanography: Physical: Ice mechanics and air/sea/ice exchange processes. Citation: Haas, C. (2004), Late-summer sea ice thickness variability in the Arctic Transpolar Drift 1991-2001 derived from ground-based electromagnetic sounding, Geophys. Res. Lett., 31, L09402, doi:10.1029/2003GL019394.

\section{Introduction}

[2] Variations of sea-ice extent and thickness are sensitive indicators of climate change. Evidence obtained from upward-looking sonars (ULS) on submarines revealed dramatic decreases of up to $43 \%$ in mean thickness of Arctic Basin sea ice between 1958-1988 and 1990-1997 [Rothrock et al., 1999; Wadhams and Davis, 2000; Tucker et al., 2001]. The decrease has been attributed to changes in atmospheric circulation and associated ice drift patterns [Zhang et al., 2000; Tucker et al., 2001; Holloway and Sou, 2002; Rigor et al., 2002]. By means of satellite radar altimetry Laxon et al. [2003] show strong interannual thickness variability of the Arctic sea ice cover south of $81.5^{\circ} \mathrm{N}$ between 1993 and 2001. In contrast to the interpretations mentioned above, the variability is solely explained by variations in the length of the preceding summer melt season, i.e., by changes in thermodynamic boundary conditions. This discussion shows a lack of understanding of the relative importance of dynamic and thermodynamic processes for the regional and temporal variability of sea ice thickness.

Copyright 2004 by the American Geophysical Union. 0094-8276/04/2003GL019394\$05.00
[3] The perennial sea-ice cover consists of a matrix of large ice floes $(0.1$ to $10 \mathrm{~km}$ diameter $)$ separated by open water leads or cracks and smaller, fragmented and often younger ice floes in between $(0.001-0.1 \mathrm{~km}$ diameter). Ice floes are composed of areas of undeformed, level ice whose thickness is determined by thermodynamic processes. They are separated by thick pressure ridges formed as a result of ice deformation and fracture. Consequently, typical ice thickness distributions possess local maxima at zero representing the amount of open water and at values representative for the typical level ice thicknesses [Thorndike et al., 1975]. They have a long, exponentially decaying tail towards thicker ice representing the abundance and thickness of pressure ridges.

[4] Here, results from drill-hole and EM thickness profiles obtained in the Transpolar Drift on single ice floes during late summer cruises of the German research icebreaker RV Polarstern are presented. Because profile layout and methodical limitations of the EM method (see below) somewhat reduce the representation of the deformed ice thickness, we focus on modal thicknesses, which are determined very accurately. Modal thickness is defined as the highest peak of the thickness distribution. We compare our results with observations from satellite radar altimetry [Laxon et al., 2003] to provide some validation and further insight into the nature of those thickness retrievals.

\section{Methods and Data Sets}

[5] The instrument and method of thickness retrieval are in detail described by Kovacs and Morey [1991], Haas et al. [1997], and Haas and Eicken [2001]. Here, all EM thickness soundings were performed with a Geonics EM31 instrument operating at $9.8 \mathrm{kHz}$ with a coil spacing of $3.66 \mathrm{~m}$. Level ice thickness estimates were shown to agree within $0.1 \mathrm{~m}$ with drill-hole measurements. The EM instrument was mounted on a sledge and pulled across ice floes, along as straight profile lines as possible and not avoiding melt ponds or pressure ridges. For practical reasons, open water and thin ice classes are thus missing in the derived thickness distributions. EM thickness retrievals are an average over a 'footprint area' of some meters in diameter. Therefore, and due to water within the blocky ridge keel structure, the maximum thickness of pressure ridges is generally underestimated, by as much as $40-50 \%$ in worst cases [Haas et al., 1997; Haas and Jochmann, 2003]. However, level ice thickness and the number and extent of ridges can be determined very well.

[6] All measurements were performed during summer cruises of RV Polarstern to the Transpolar Drift (Table 1). 
Table 1. Summary of Ice Thickness Measurements

\begin{tabular}{|c|c|c|c|c|c|c|c|c|c|c|}
\hline Year & Months & $\begin{array}{c}\text { No } \\
\text { of } \\
\text { floes }\end{array}$ & $\begin{array}{l}\text { Mean } \\
\text { length } \\
(\mathrm{m})\end{array}$ & $\begin{array}{c}\text { Total } \\
\text { length } \\
(\mathrm{km})\end{array}$ & $\begin{array}{c}\text { Regional } \\
\text { coverage } \\
(\mathrm{km})\end{array}$ & Data type & $\begin{array}{l}\text { Pooled modal } \\
\text { thickness } \\
(\mathrm{m} ; \text { Figure } 4)^{\mathrm{a}}\end{array}$ & $\begin{array}{c}\text { Mean } \\
\text { thickness } \\
(\mathrm{m})^{\mathrm{b}}\end{array}$ & $\begin{array}{l}\text { Mean modal } \\
\text { thickness } \\
(\mathrm{m})^{\mathrm{b}}\end{array}$ & Reference $^{\mathrm{a}}$ \\
\hline 1991 & Aug/Sep & 50 & 50 & 2.5 & 1100 & Drill only & 2.50 & $3.11 \pm 1.03$ & $2.72 \pm 0.69$ & Eicken et al. [1995] \\
\hline 1996 & Aug & 5 & 956 & 4.8 & 400 & EM, drill & 2.45 & $3.11 \pm 1.12$ & $2.34 \pm 0.24$ & Haas and Eicken [2001] \\
\hline 1998 & July & 43 & 100 & 4.3 & 1250 & EM & 2.10 & $2.88 \pm 1.49$ & $2.24 \pm 0.13$ & \\
\hline 2001 & Aug/Sep & 48 & 2297 & 110.2 & 800 & EM, drill & 1.95 & $2.41 \pm 0.98$ & $1.99 \pm 0.30$ & \\
\hline
\end{tabular}

${ }^{a}$ Pooled mode is the modal thickness of all thickness distributions of one year taken together (Figure 4). The mean mode refers to the average of the modes of all floes of a single year.

${ }^{\mathrm{b}}$ Mean \pm 1 standard deviation.

A total of 146 large ice floes were arbitrarily chosen and accessed either directly from the ship or by helicopter (Figure 1), and profiled with a point spacing of $5 \mathrm{~m}$ (Figure 2). The 1991 data were previously published by Eicken et al. [1995], and the 1996 data are identical to the Northern Central Arctic data of Haas and Eicken [2001]. In 1996 and 2001, the EM calibration was confirmed on almost every floe by means of 11 drillhole measurements (Figure 2). Note the substantial increase of number of measurements per year due to improving operability of the EM method.

[7] The ice thickness distribution was computed as a probability density function (pdf) for every ice floe and then averaged over all pdfs from the same year. This removed any bias due to variable profile lengths.

[8] For better comparison with ice thicknesses retrieved from satellite radar altimetry [Laxon et al., 2003], we

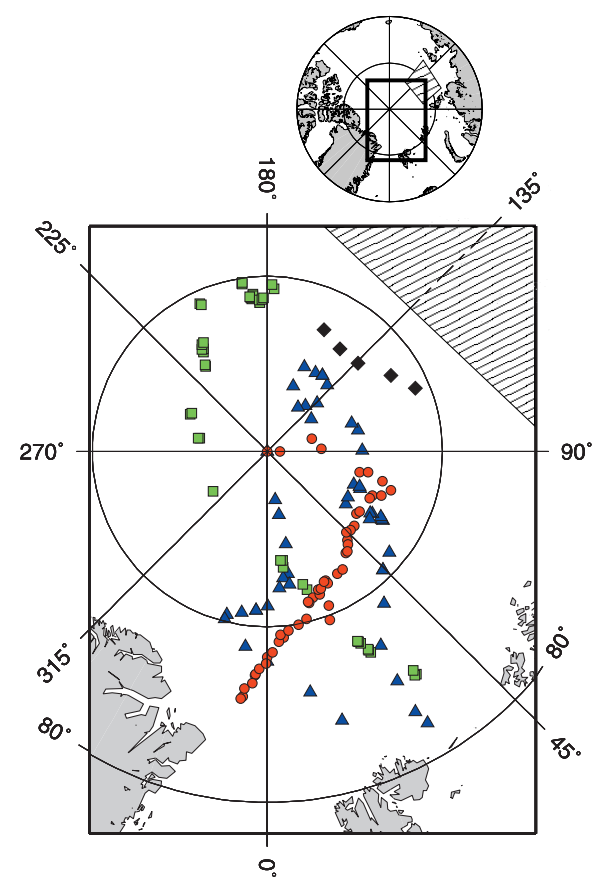

Figure 1. Map of the Central Arctic Ocean showing the locations of ice floes surveyed in $1991(\triangle), 1996(\diamond), 1998$ $(\square)$, and $2001(\bigcirc)$. Hatched area shows region of thickness surveys north of the Laptev Sea in 1993, 1995, and 1996 [Haas and Eicken, 2001]. extend our data set by measurements of late-summer firstyear ice thickness in 1993, 1995, and 1996 in the Laptev Sea, the source region of the Transpolar Drift. These data were gathered exactly as described above and were published by Haas and Eicken [2001] before.

\section{Thickness Variability in the Transpolar Drift, 1991-2001}

[9] Figure 3 shows the modal ice thickness of all single floes profiled in 2001 against longitude, more or less coinciding with a transect along the Transpolar Drift (Figure 1). There is quite some scatter between modes of single ice floes, averaging at $1.99 \pm 0.30 \mathrm{~m}$, which was also typical for the other years (Table 1). However, linear regression shows that there is no significant regional trend in the study region (Figure 3). This justifies the above procedure of averaging all pdfs from one year to compute the annual thickness distribution.

[10] Figure 4 presents the overall thickness distributions thus derived. The sharpness of the modes of the distributions shows that even the smaller data sets represent well the modal ice thickness. Modal ice thickness has decreased from $2.50 \mathrm{~m}$ in 1991 to $1.95 \mathrm{~m}$ in 2001. Similarly, mean thickness decreased from $3.11 \mathrm{~m}$ in 1991 to $2.41 \mathrm{~m}$ in 2001 (Table 1). Considering that the 1998 measurements were performed in July, i.e., in the middle of the ablation season, those thicknesses would actually become similar to values

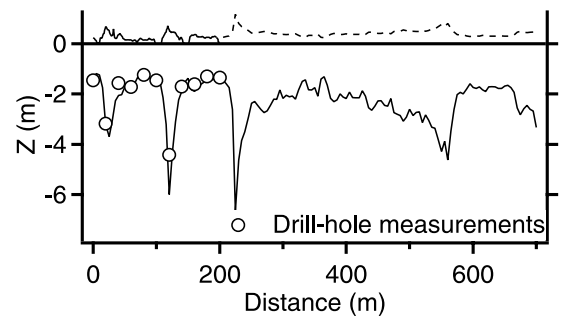

Figure 2. Typical ground-based EM thickness profile of a multiyear ice floe in the Transpolar Drift. Sea level is at $\mathrm{Z}=$ $0.00 \mathrm{~m}$. The lines show freeboard (above sea level) and draft (below). Freeboard along the first $200 \mathrm{~m}$ of profile was obtained by surveying. Beyond $200 \mathrm{~m}$, freeboard (stippled line) and draft were computed from ice thickness assuming an ice density of $880 \mathrm{~kg} \mathrm{~m}^{-3}$ and isostatic equilibrium. Circles show drill-hole thicknesses. 


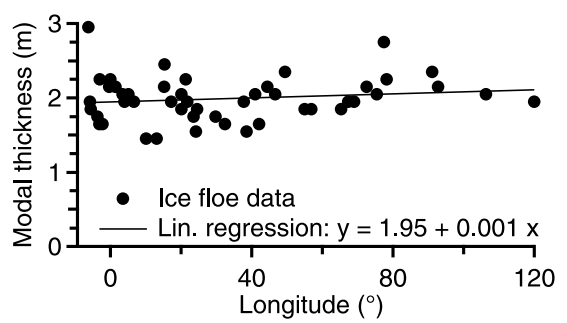

Figure 3. Modal ice thickness of all floes profiled in 2001 versus longitude (cf. Figure 1).

from 2001 if they were adjusted for likely thinning during the summer [Rothrock et al., 1999].

\section{Comparison of Interannual Thickness Variability in the Transpolar Drift and South of $81.5^{\circ} \mathrm{N}$}

[11] The average modal thickness in the Transpolar Drift in $1991,1996,1998$, and 2001 was $2.20 \pm 0.21 \mathrm{~m}$. This was subtracted from each year's modal thickness to derive the thickness anomaly of that year. Similarly, in 1993, 1995, and 1996, in the Laptev Sea the average modal first-year ice thickness was $1.5 \pm 0.32 \mathrm{~m}$ [Haas and Eicken, 2001], and anomalies were computed by subtracting this from each year's thickness. The resulting time series of thickness anomalies is shown in Figure 5. It can be seen that 1996 was a year with thick ice both in the Transpolar Drift and in the Laptev Sea. In contrast, in 1995 ice thickness was minimal in the Laptev Sea, and it is likely that it was small in the Transpolar Drift, too [Haas and Eicken, 2001].

[12] Figure 5 also shows mean winter (October to March) ice thickness anomalies presented by Laxon et al. [2003, Figure 3a] from satellite radar altimetry. For methodical reasons, there are no summer altimetric data. Due to the satellite orbit, these observations are limited to regions

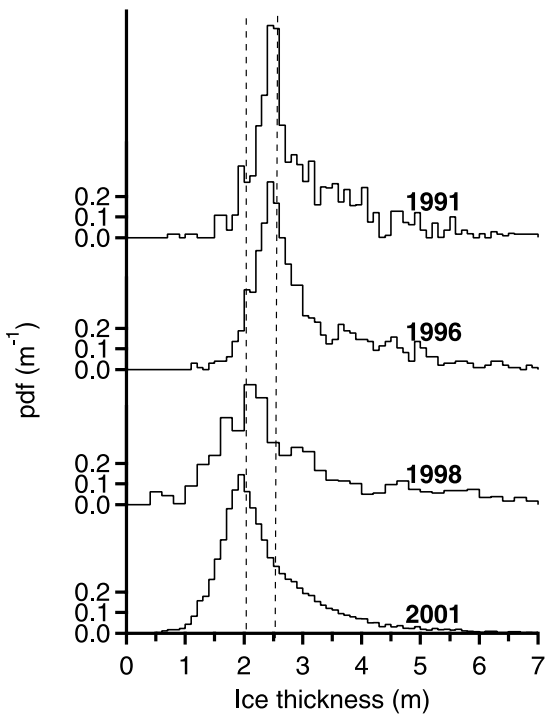

Figure 4. Ice thickness distributions (pdfs: probability density functions) of ice floes in the Transpolar Drift (Figure 1) in 1991, 1996, 1998, and 2001. Dashed lines at 2 and $2.5 \mathrm{~m}$ shown as a reference. south of $81.5^{\circ} \mathrm{N}$, but comprise the whole circumarctic sea ice cover. Note that except in the Laptev Sea, there is no regional overlap with the EM measurements. Every winter's mean thickness is plotted at the year of the preceding summer to synchronize it with the respective EM measurement. There are coincident measurements in 1993, 1995, 1996 (two samples) and 1998. There is good correlation of $\mathrm{r}^{2}=0.73$ between anomalies of late-summer EM modal thickness and winter mean thickness obtained from radar altimetry. If the two EM anomalies in 1996 are averaged, the correlation improves only slightly to 0.76 . The latesummer EM mean thickness shows no correlation with the altimetric data.

\section{Discussion and Conclusion}

[13] This study shows that accurate and representative regional ice thickness data can be gathered by ground-based EM measurements, and thus provide important observations of a changing Arctic ice cover. As measurements are easily and quickly performed, they should also be carried out whenever possible during Arctic scientific cruises, and even from tourist cruises to extend the existing time series. Although open water and thin ice fractions are missing, and ridged ice is poorly represented, we assume that the thickness distributions shown in Figure 4 and by Haas and Eicken [2001] represent $80-90 \%$ of the ice floes in a certain region. Comparison of ice thickness profiles from the same year and region shows that there is quite some variability of thickness statistics between floes even with profiles longer than $500-1000 \mathrm{~m}$. On the one hand, this scatter is due to the presence of floes of different age, although the majority of ice floes might have formed in the same winter. However, in a divergent ice field new ice forms when leads and polynyas open within an ice cover of older floes. For example, Haas and Eicken [2001] demonstrate that large polynyas can open in the Central Arctic Ocean in summer, and increased divergence is also a consequence of a cyclonic circulation regime, typical for the 1990s [Holloway and Sou, 2002; Rigor et al., 2002]. Clearly, the ice in the Transpolar Drift therefore represents a mixture of multi-, second-, and first year floes, with decreasing frequency of occurrence from the former to the latter.

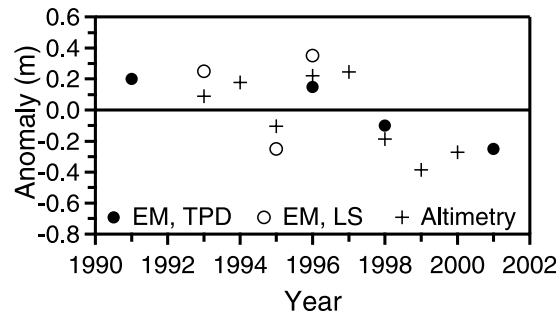

Figure 5. Time series of Arctic ice thickness anomalies obtained by EM sounding (circles) and satellite radar altimetry (crosses; Laxon et al. [2003]). Typical latesummer EM data were obtained in the Transpolar Drift (TPD, closed circles; this study) and in the Laptev Sea (LS, open circles, Haas and Eicken [2001]). Mean winter altimetry data are plotted at the year of the preceding summer. 
[14] On the other hand, the scatter observed with each years modal thicknesses is also due to varying degrees of deformation and different amounts of small scale surface roughness, e.g., due to variable surface ablation and melt ponding [Haas and Eicken, 2001; Eicken et al., 2002; Perovich et al., 2003]. These cause a considerable roughness of single floe profiles and sometimes even obscure the occurrence of a clear mode in the ice floes thickness distributions. In contrast, modal thicknesses of first-year floes in the Laptev Sea without any surface melting scattered only little [Haas and Eicken, 2001]. The variability between floes suggests that it is more important to profile a larger number of floes than to survey longer profiles on fewer floes.

[15] There were no spatial trends observed along the Transpolar Drift. In fact, other measurements outside this region (Figure 1) were excluded in the present analysis, because they obviously belonged to different ice regimes (regions with consistently different ice thickness statistics, e.g., exclusively first-year ice in the Laptev Sea or towards the ice margin in this case) and would have blurred the thickness distributions in Figure 4. The same differentiation between ice regimes was performed by Haas and Eicken [2001]. Although the ice cover consists of a mixture of floes of different age, the mean ice age increases downstream the Transpolar Drift with increasing age of the oldest floes. The absence of a thickness trend could therefore suggest that, on a larger scale, the ice reaches some thermodynamic equilibrium thickness already after its second freezing season [Maykut and Untersteiner, 1971].

[16] Results presented here show a strong interannual variability of ice thicknesses in the Transpolar Drift. Modal ice thickness varies by as much as $22 \%$ between 1991 and 2001. Modal ice thickness represents the thickness of level ice, which is mostly a function of thermodynamic conditions [Thorndike et al., 1975]. Unfortunately, the present data cannot distinguish between amplitudes of winter ice growth and summer ablation, which determine ice thickness at the end of summer. Thus, thinner ice in 2001 may have been caused by either reduced ice growth in the previous winter, or by increased ice melt in the preceding summer.

[17] However, Laxon et al. [2003] show a striking correlation between ice thickness and preceding summer melt season length. As there is good correlation between their and our data even though they have been derived from different regions, in fact variable summer melt intensity could also be the main cause for the variability in our data. The good agreement of thickness anomalies in different regions might also show that melt season intensity is more an arctic-wide than a regional phenomenon. Similarly, Haas and Eicken [2001] had attributed the thickness variability in the Laptev Sea in 1993, 1995, and 1996 to variations in the amount of summer surface melt, too. However, these differences were driven by distinctly different atmospheric circulation regimes during the summers of those years. Thus, the cause for variable surface melt intensities still remains to be investigated, as it is dependent on both thermodynamic and atmospheric circulation conditions.

[18] Although there was some $22 \%$ thinning over the observation period, the ten-year period is much too short to determine any significant ice thickness trend. It should be noted that the variability observed between 1991 and 2001 of $0.73 \mathrm{~m}$ in mean and $0.55 \mathrm{~m}$ in modal thickness is much smaller than changes of mean thickness observed over decadal scales of $1.3 \mathrm{~m}$ [Rothrock et al., 1999] to $1.5 \mathrm{~m}$ [Tucker et al., 2001]. Similarly, in a model study Holloway and Sou [2002] show decadal changes of mean ice thickness by as much as $1.5 \mathrm{~m}$. Thus, the observed variability shown here might just be a superimposed thermodynamic variability on a much larger and long period decadal variability due to ice dynamics changes affecting the frequency and thickness of pressure ridges. It should also be noted that there is no correlation between anomalies of modal thickness observed here (Figure 3 ) and anomalies of mean thickness derived by Winsor [2001; Table 1] from ULS data from the North Pole between 1991 and 1998. However, the interannual variability in both data sets is similar.

[19] The study of Laxon et al. [2003] is the first ever to retrieve sea ice thickness from satellite radar altimetry. However, thickness retrieval from these measurements is not straightforward, and it remains unclear whether these retrievals represent the mean, the mode, the maximum or some other thickness statistic in the radar altimeter footprint. The good correlation with modal thickness anomalies presented here, as well as the sensitivity to summer melt suggests that the radar altimeter data mostly represent modal ice thickness, and that EM sounding is a highly suitable tool for validation of those measurements.

[20] Acknowledgments. We are very grateful for numerous colleagues who have contributed to the collection of the extensive data, in particular Jörg Bareiss, Jan Lieser, and Estella Weigelt. A careful review by Drew Rothrock considerably improved the manuscript. This work was supported by the SITHOS project (Sea Ice Thickness Observation System), EU EVK2-2001-00236.

\section{References}

Eicken, H., M. Lensu, M. Leppäranta, W. B. Tucker, A. J. Gow, and O. Salmela (1995), Thickness, structure and properties of level summer multi-year ice in the Eurasian Sector of the Arctic Ocean, J. Geophys. Res., 100(C11), 22,697-22,710.

Eicken, H., H. R. Krouse, D. Kadko, and D. K. Perovich (2002), Tracer studies of pathways and rates of meltwater transport through Arctic summer sea ice, J. Geophys. Res., 107(C10), 8046, doi:10.1029/ 2000JC000583.

Haas, C., S. Gerland, H. Eicken, and H. Miller (1997), Comparison of seaice thickness measurements under summer and winter conditions in the Arctic using a small electromagnetic induction device, Geophysics, 62, $749-757$.

Haas, C., and H. Eicken (2001), Interannual variability of summer sea ice thickness in the Siberian and Central Arctic under different atmospheric circulation regimes, J. Geophys. Res., 106(C3), 4449-4462.

Haas, C., and P. Jochmann (2003), Continuous EM and ULS thickness profiling in support of ice force measurements, in Proceedings of the 17th International Conference on Port and Ocean Engineering under Arctic Conditions, POAC '03, Trondheim, Norway, edited by S. Loeset, B. Bonnemaire, and M. Bjerkas, Dept. of Civil and Transport Engineering, Norwegian Univ. of Science and Technology NTNU, Trondheim, Norway, Vol. 2, 849-856.

Holloway, G., and T. Sou (2002), Has Arctic sea ice rapidly thinned?, J. Clim., 15, 1691-1701.

Kovacs, A., and R. M. Morey (1991), Sounding sea-ice thickness using a portable electromagnetic induction instrument, Geophysics, 56, 1992 1998.

Laxon, S., N. Peacock, and D. Smith (2003), High interannual variability of sea ice thickness in the Arctic region, Nature, 425, 947-950.

Maykut, G. A., and N. Untersteiner (1971), Some results from a time dependent thermodynamic model of sea ice, J. Geophys. Res., 76(6), $1550-1575$.

Perovich, D. K., T. C. Grenfell, B. Light, J. Richter-Menge, W. B. Tucker III, and H. Eicken (2003), Thin and thinner: Ice mass balance measurements 
during SHEBA, J. Geophys. Res., 108(C3), 8050, doi:10.1029/ 2001JC001079.

Rigor, I. G., J. M. Wallace, and R. L. Colony (2002), On the response of sea ice to the Arctic Oscillation, J. Clim., 15, 2648-2668.

Rothrock, D. A., Y. Yu, and G. A. Maykut (1999), Thinning of the Arctic sea-ice cover, Geophys. Res. Lett., 26(23), 3469-3472.

Thorndike, A. S., D. A. Rothrock, G. A. Maykut, and R. Colony (1975), The thickness distribution of sea ice, J. Geophys. Res., 80(33), 45014513

Tucker, W. B., J. W. Weatherly, D. T. Eppler, L. D. Farmer, and D. L. Bentley (2001), Evidence for rapid thinning of sea ice in the western Arctic Ocean at the end of the 1980s, Geophys. Res. Lett., 28(14), 28512854.
Wadhams, P., and N. R. Davis (2000), Further evidence of thinning in the Arctic Ocean, Geophys. Res. Lett., 27(24), 3973-3975.

Winsor, P. (2001), Arctic sea ice thickness remained constant during the 1990's, Geophys. Res. Lett., 28(6), 1039-1041.

Zhang, J., D. Rothrock, and M. Steele (2000), Recent changes in Arctic sea ice: The interplay between ice dynamics and thermodynamics, J. Clim., $13,3099-3114$

C. Haas, Alfred Wegener Institute for Polar and Marine Research, Bussestrasse 24, D-27570 Bremerhaven, Germany. (chaas@awi-bremerhaven. de) 